\title{
Myocardial injury in diabetic patients with multivessel coronary artery disease after revascularization interventions
}

\author{
Paulo Cury Rezende, Whady Hueb*, Rosa Maria Rahmi, Thiago Luis Scudeler, \\ Diogo Freitas Cardoso de Azevedo, Cibele Larrosa Garzillo, Carlos Alexandre Wainrober Segre, \\ Jose Antonio Franchini Ramires and Roberto Kalil Filho
}

\begin{abstract}
Background: Diabetic patients may be more susceptible to myocardial injury after coronary interventions. Thus, the aim of this study was to assess the release of cardiac biomarkers, CK-MB and troponin, and the findings of new late gadolinium enhancement (LGE) on cardiac magnetic resonance (CMR) in patients with type 2 diabetes mellitus after elective revascularization procedures for multivessel coronary artery disease (CAD).

Methods: Patients with multivessel CAD and preserved systolic ventricular function underwent either elective percutaneous coronary intervention ( $\mathrm{PCl}$ ), off-pump or on-pump bypass surgery (CABG). Troponin and CK-MB were systematically collected at baseline, 6, 12, 24, 36, 48 and $72 \mathrm{~h}$ after the procedures. CMR with LGE was performed before and after the interventions. Patients were stratified according to diabetes status at study entry. Biomarkers and CMR results were compared between diabetic and nondiabetics patients. Analyses of correlation were also performed among glycemic and glycated hemoglobin (A1C) levels and troponin and CK-MB peak levels. Patients were also stratified into tertiles of fasting glycemia and A1c levels and were compared in terms of periprocedural myocardial infarction (PMI) on CMR.

Results: Ninety $(44.5 \%)$ of the 202 patients had diabetes mellitus at study entry. After interventions, median peak troponin was $2.18(0.47,5.14)$ and $2.24(0.69,5.42) \mathrm{ng} / \mathrm{mL}(P=0.81)$, and median peak CK-MB was $14.1(6.8,31.7)$ and 14.0 $(4.2,29.8) \mathrm{ng} / \mathrm{mL}(P=0.43)$, in diabetic and nondiabetic patients, respectively. The release of troponin and CK-MB over time was statistically similar in both groups and in the three treatments, besides PCI. New LGE on CMR indicated that new myocardial fibrosis was present in 18.9 and $17.3 \%(P=0.91)$, and myocardial edema in 15.5 and $22.9 \%(P=0.39)$ in diabetic and nondiabetic patients, respectively. The incidence of PMI in the glycemia tertiles was $17.9 \%$ versus $19.3 \%$ versus $18.7 \%(P=0.98)$, and in the A1c tertiles was $19.1 \%$ versus $13.3 \%$ versus $22.2 \%(P=0.88)$.

Conclusions: In this study, diabetes mellitus did not add risk of myocardial injury after revascularization interventions in patients with multivessel coronary artery disease.

Trial Registration Name of Registry: Evaluation of cardiac biomarker elevation after percutaneous coronary intervention or coronary artery bypass graft; URL: http://www.controlled-trials.com.ISRCTN09454308
\end{abstract}

Keywords: Type 2 diabetes mellitus, Coronary artery disease, Percutaneous coronary intervention, Coronary artery bypass, Myocardial infarction

\footnotetext{
*Correspondence: whady.hueb@incor.usp.br; mass@incor.usp.br Heart Institute (InCor) of the University of São Paulo, Avenida Dr. Eneas de Carvalho Aguiar, 44, AB sala 114, Cerqueira César, São Paulo, SP CEP 05403-900, Brazil
} 


\section{Background}

Myocardial revascularization interventions are routinely indicated during the course of the treatment of patients with chronic coronary artery disease (CAD). The most important benefit observed with these interventions is the improvement in angina and exercise capacity in patients with limiting symptoms $[1,2]$.

However, during these interventions, myocardial damage may occur, and this may also influence outcomes during follow-up [3]. Periprocedural myocardial injury (PMI) has been extensively studied but is still not completely understood. The diagnosis is still challenging, and the appropriate treatment is yet to be defined. Especially with the emergence of highly sensitive markers of myocardial necrosis, the diagnosis of myocardial injury and infarction after coronary interventions has become even more debatable $[4,5]$.

Many known and unknown factors may influence myocardial injury following interventions. Although this is still controversial, diabetes mellitus may change myocardial functions and potentially make the myocardium more susceptible to ischemic injuries [6].

Experimental studies that addressed this question have shown contradictory results about the ischemic myocardial sensitivity of diabetic animal models. While some studies have demonstrated higher cardiac damage after ischemic insults $[7,8]$, others have shown no differences [9] or even a protective role of diabetes [10-12].

Additionally, clinical studies in the scenario of acute coronary syndromes have shown indirect evidence of a higher susceptibility of diabetic patients to such things as greater risk for the development of heart failure [13] and higher morbidity and mortality rates [14]. However, uncertainties still remain about whether these are caused by a higher sensitivity to myocardial ischemia due to diabetes mellitus, or if these are related to other reasons such as more diffuse and aggressive coronary disease or due to the microvascular complications potentially caused by diabetes. Moreover, direct evidence from human studies about myocardial responses to ischemic insults in diabetic populations is still inconclusive and scarce.

In this context, the medicine, angioplasty or surgery study $\mathrm{V}$ is a prospective trial that assessed myocardial injury after myocardial revascularization interventions in patients with chronic multivessel CAD who underwent percutaneous coronary intervention (PCI), on-pump, or off-pump coronary artery bypass surgery (CABG) [15]. Cardiac biomarkers, troponin, and CK-MB were systematically collected before and after procedures to assess myocardial injury by the perspective of high-sensitive biomarkers released after interventions. Patients also underwent cardiac magnetic resonances (CMR) with late gadolinium enhancement (LGE) before and after procedures to assess new areas of myocardial infarction by the perspective of a high-sensitive imaging study. In this post hoc analysis, myocardial injury was analyzed in patients with type 2 diabetes mellitus and compared with patients without diabetes.

\section{Methods}

The medicine, angioplasty, or surgery study V (MASS-V) is a prospective nonrandomized trial that aimed at studying PMI after PCI, on-pump, or off-pump CABG [15]. Patients with angiographically documented multivessel coronary stenosis of more than $70 \%$ by visual assessment and myocardial ischemia due to angina symptoms or positive stress tests were included. Only patients with stable symptoms and preserved systolic ventricular function were included. They were excluded if they have experienced a recent acute coronary syndrome or other thromboembolic phenomena in the last 3 months, systemic inflammatory disease, or kidney dysfunction (creatinine above $2.0 \mathrm{mg} / \mathrm{mL}$ ).

\section{Cardiac biomarkers}

Blood samples were collected for troponin I (TnI) and CK-MB measurement before procedures and 6, 12, 24, 36, and $48 \mathrm{~h}$ after PCI. After on-pump or off-pump CABG, these biomarkers were measured before and 6 , $12,24,36,48$, and $72 \mathrm{~h}$ after surgery.

All samples were centrifuged at $3000 \mathrm{rpm}$ for $20 \mathrm{~min}$ and analyzed within $2 \mathrm{~h}$ after collection. Analyses of TnI and CK-MB were performed using an ADVIA Centaur immunoassay analyser (Siemens Health Care Diagnostics, Tarrytown, NY). According to the manufacturer, the lower limit of detection of TnI using the high-sensitivity Ultra kit is $0.006 \mathrm{ng} / \mathrm{mL}$, and the 99th percentile upper reference limit (URL) is $0.04 \mathrm{ng} / \mathrm{mL}$. The assay precision represented by the percentage coefficient of variation is $10 \%$ at $0.03 \mathrm{ng} / \mathrm{mL}$. The detection limit of the CK-MB mass kit is $0.18 \mathrm{ng} / \mathrm{mL}$. Cutoff values at the 99th percentile are $3.8 \mathrm{ng} / \mathrm{mL}$ for women and $4.4 \mathrm{ng} / \mathrm{mL}$ for men. The coefficients of variations for CK-MB mass as specified by the manufacturer are $3.91 \%$ at $3.55 \mathrm{ng} / \mathrm{mL}$ and $3.67 \%$ at $80.16 \mathrm{ng} / \mathrm{mL}$. These measurements are in accordance with the recommendations of the Study Group on Biomarkers in Cardiology of the European Society of Cardiology Working Group on Acute Cardiac Care [16].

\section{Cardiac magnetic resonance}

Every patient underwent a CMR before and after interventions during the hospitalization period. They were studied in a 1.5-T Achieva Magnetic Resonance scanner (Philips Healthcare, Andover, MA). Steady-state freeprocession cine images were acquired in two long-axis 
(two and four chambers) views and 8-10 short-axis views of the left ventricle. Contrast-enhanced images were acquired in long- and short-axis planes identical to the cine images. Typical voxel size was $1.6,2.1$, and $8 \mathrm{~mm}$, with a reconstruction matrix of 528 and a reconstructed voxel size of $0.6 \mathrm{~mm}$. Myocardial infarction was defined as the identification of hyperenhancement in the myocardium on CMR. Infarcted regions exhibit this phenomenon, which might be due to an increased volume of distribution of the contrast agent, because of rupture of myocyte membranes and slow contrast washout.

The areas of late gadolinium hyperenhancement were measured by two experienced and independent observers blinded to the intervention technique and biomarker data. When measurements differed, a third observer performed a review, and a consensus was obtained. Hyperenhanced pixels were defined as those with image intensities exceeding two standard deviations greater than the mean of image intensities in a remote myocardial region in the same image. Preintervention and postintervention scans were read side by side in the three intervention groups.

\section{Definition of type 2 diabetes mellitus}

Patients were considered to have diabetes if, at baseline, they were using insulin and/or oral hypoglycemic agents, of if they had the classical criteria for type 2 diabetes mellitus as stated by the American Diabetes Association [17] (two fasting glucose measures $\geq 126 \mathrm{mg} / \mathrm{dL}$, glycated hemoglobin $[\mathrm{A} 1 \mathrm{c}] \geq 6.5 \%$, random glucose $\geq 200 \mathrm{mg} / \mathrm{dL}$, or 2-h plasma glucose $\geq 200 \mathrm{mg} / \mathrm{dL}$ during an oral glucose tolerance test).

\section{Statistical analysis}

Categorical data are presented as percentages and continuous data as means \pm standard deviations, or as medians and interquartile ranges, as appropriate. Categorical data were compared using the Chi square test or Fisher's exact test. Continuous variables were tested regarding their distribution with the Shapiro-Wilk test. Those normally distributed were compared using the unpaired $t$ test and if not normally distributed by Wilcoxon ranksum test. The comparison of troponin and CK-MB over time between diabetic and nondiabetic patients was also performed using the Wilcoxon rank-sum test. Analyses of correlations were performed among glycemia and A1c levels and troponin and CK-MB, and nonparametric Spearman's correlation coefficients were calculated with their $95 \%$ confidence intervals. All tests were 2 -sided and a $P$ value $<0.05$ was considered statistically significant. Graphs were created in Graphpad Prism 7.0a, 2016, and all analyses were performed using R software (2016, R Foundation for Statistical Computing, Vienna, Austria, URL https://www.R-project.org/).

\section{Results}

Between May 2012 and March 2014, 326 patients with multivessel CAD were analyzed for study enrollment. From these, 219 were included in this prospective, singlecenter, nonrandomized trial and were assigned to PCI, on-pump or off-pump CABG. Seventeen patients were excluded after the procedures (11 due to claustrophobia during CMR, four due to cerebrovascular accidents, and two due to septicemia). Thus, 202 patients were analyzed in this study. Of these, 66 were assigned to PCI, 67 to offpump, and 69 to on-pump CABG. Ninety patients (44.5\%) had diabetes mellitus at study entry. The baseline characteristics of diabetic and nondiabetic patients are presented in Table 1. Both groups were statistically similar regarding main demographic characteristics, despite glycemic levels. Table 2 shows the SYNTAX scores of patients with and without diabetes, stratified by treatment groups.

\section{Biomarkers and CMR assessment}

The study protocol assessed troponin and CK-MB at baseline, 6, 12, 24, 36, and $48 \mathrm{~h}$ after PCI and in the same periods up to $72 \mathrm{~h}$ after on-pump and off-pump CABG in 202 CAD patients. A total of 2658 biomarker samples were analyzed in this study.

After PCI, we analyzed 386 troponin samples until $48 \mathrm{~h}$ (97.5\% of all 396 possible measurements). Regarding

\section{Table 1 Baseline demographic variables of diabetic and nondiabetic patients in the MASS V trial}

\begin{tabular}{|c|c|c|c|}
\hline & $\begin{array}{l}\text { Diabetic patients } \\
n=90\end{array}$ & $\begin{array}{l}\text { Nondiabetic patients } \\
n=112\end{array}$ & $P$ \\
\hline Male (\%) & 68.9 & 66.1 & 0.78 \\
\hline Age $(\text { year) })^{\mathrm{a}}$ & $62.5(55.0,67.75)$ & $62.0(56.0,68.0)$ & 0.96 \\
\hline Hypertension (\%) & 86.7 & 83.0 & 0.61 \\
\hline Prior MI (\%) & 31.1 & 33.0 & 0.89 \\
\hline Angina (\%) & 89.9 & 89.3 & 1.0 \\
\hline 3-Vessel CAD (\%) & 72.2 & 62.5 & 0.28 \\
\hline LAD disease (\%) & 88.9 & 90.2 & 0.95 \\
\hline LM disease (\%) & 20.0 & 25.9 & 0.41 \\
\hline SYNTAX score ${ }^{a}$ & $21.0(16.0,26.9)$ & $19.0(14.0,25.0)$ & 0.27 \\
\hline $\mathrm{EF}^{\mathrm{a}}$ & $0.67(0.61,0.75)$ & $0.67(0.61,0.72)$ & 0.56 \\
\hline Cholesterol $^{\mathrm{a}}$ & $165.0(134.0,189.0)$ & $168.0(147.5,197.0)$ & 0.18 \\
\hline LDL-Cholest ${ }^{\mathrm{a}}$ & $93.0(72.0,117.0)$ & $98.0(78.0,120.8)$ & 0.17 \\
\hline HDL-Cholest ${ }^{\mathrm{a}}$ & $37.0(30.0,42.0)$ & $35.0(29.3,46.0)$ & 0.74 \\
\hline Triglycerides $^{\mathrm{a}}$ & $134.0(91.0,196.0)$ & $128.0(96.5,167.5)$ & 0.95 \\
\hline Glucose $e^{a}$ & $146.5(116.2,194.5)$ & $100.0(94.0,112.0)$ & $<0.001$ \\
\hline $\mathrm{A} 1 \mathrm{C}^{\mathrm{a}}$ & $6.9(6.05,8.50)$ & - & - \\
\hline Creatinine $^{a}$ & $1.00(0.88,1.22)$ & $0.98(0.85,1.20)$ & 0.65 \\
\hline
\end{tabular}

$M I$ myocardial infarction, $C A D$ coronary artery disease, $L A D$ left anterior descending coronary artery, $L M$ left main coronary artery, $E F$ ejection fraction, LDL low-density lipoprotein, $H D L$ high-density lipoprotein, A1c glycated hemoglobin

a Presented as median (25th, 75th percentile) 
Table 2 SYNTAX scores in patients with and without diabetes, in the three treatment groups

\begin{tabular}{llll}
\hline & On-pump CABG & Off-pump CABG & PCI \\
\hline Diabetic patients & $24.0(18.0,30.0)$ & $21.0(15.5,25.5)$ & $18.0(11.0,22.7)$ \\
$\begin{array}{l}\text { Nondiabetic } \\
\text { patients }\end{array}$ & $25.0(18.7,31.4)$ & $19.0(14.7,23.0)$ & $15.5(11.0,20.7)$ \\
\hline
\end{tabular}

Data is presented as median (25th, 75th percentile)

$C A B G$ coronary artery bypass graft surgery, $P C l$ percutaneous coronary intervention

CK-MB, we analyzed 383 samples (96.7\% of all 396 possible samples).

After on-pump and off-pump CABG, we analyzed 942 troponin samples until 72 h $(98.9 \%$ of all 952 possible measurements). Regarding CK-MB, we analyzed 947 samples (99.5\% of all 952 possible samples).

All 202 patients underwent 2 CMRs with LGE, and thus 404 CMRs were analyzed regarding new areas of myocardial fibrosis and myocardial edema after coronary interventions.

\section{Troponin results}

The group of diabetic patients had a mean peak troponin of $5.38 \mathrm{ng} / \mathrm{mL}$ with a standard deviation of $9.49 \mathrm{ng} / \mathrm{mL}$, and a median and interquartile range (IQR) of $2.18 \mathrm{ng} /$ $\mathrm{mL}(0.47,5.14)$. The group of nondiabetic patients had a mean peak troponin of $5.91 \mathrm{ng} / \mathrm{mL}$ with a standard deviation of $9.88 \mathrm{ng} / \mathrm{mL}$, and median and IQR of $2.24 \mathrm{ng} / \mathrm{mL}$ $(0.69,5.42)$. The total area under the curve was also statistically similar between both groups $(P=0.97)$.

We also compared troponin values at baseline and during each time point $(6,12,24,36,48$, and $72 \mathrm{~h})$ between diabetic and nondiabetic patients and separately for each cardiac procedure (Fig. 1).

\section{CK-MB results}

The group of diabetic patients had a mean peak CK-MB of $27.8 \mathrm{ng} / \mathrm{mL}$ with a standard deviation of $37.3 \mathrm{ng} / \mathrm{mL}$, and a median and IQR of $14.1 \mathrm{ng} / \mathrm{mL}(6.8,31.7)$. The group of nondiabetic patients had a mean peak CK-MB of $25.2 \mathrm{ng} / \mathrm{mL}$ with a standard deviation of $34.1 \mathrm{ng} / \mathrm{mL}$, and median and IQR of $14.0 \mathrm{ng} / \mathrm{mL}(4.2,29.8), P=0.43$. The total area under the curve was also statistically similar in both groups $(P=0.56)$.

We also compared CK-MB values at baseline and during each time point $(6,12,24,36,48$, and $72 \mathrm{~h})$ between diabetic and nondiabetic patients and separately for each cardiac procedure (Fig. 2).

\section{CMR results}

New LGE on CMR indicating new myocardial fibrosis after interventions was present in $18.9 \%$ and $17.3 \%$
$(P=0.91)$, and myocardial edema in $15.5 \%$ and $22.9 \%$ $(P=0.39)$ in diabetic and nondiabetic patients, respectively (Fig. 3).

\section{Analyses of correlation}

Peak CK-MB and peak troponin were plotted against fasting glycemic and A1c levels to look for any correlations among these variables. Glycemic levels and peak troponin had a very weak negative correlation ( $\mathrm{r}=-0.08,95 \% \mathrm{CI}-0.22$ to $0.07, P=0.28)$. Glycemic levels and peak CK-MB also had a very weak correlation ( $\mathrm{r}=0.01,95 \% \mathrm{CI}-0.13$ to $0.16, P=0.85$ ).

The analysis of correlation of A1c levels from diabetic patients also showed a very weak negative correlation with peak troponin and CK-MB levels $(r=-0.18,95 \%$ $\mathrm{CI}-0.38$ to $0.03, P=0.08$ for troponin; $\mathrm{r}=-0.14,95 \%$ $\mathrm{CI}-0.34$ to $0.08, P=0.20$ for $\mathrm{CK}-\mathrm{MB})$.

\section{Periprocedural myocardial infarction on CMR according to tertiles of glycemia and A1c levels}

Of 202 patients, 200 had their baseline glycemia measured. These patients were grouped into tertiles of glycemia $(<131, \mathrm{n}=134 ; 131-179, \mathrm{n}=31 ; \geq 180, \mathrm{n}=32)$. No difference was found regarding PMI on CMR (17.9\% versus $19.3 \%$ versus $18.7 \%, P=0.98)$. These results are shown in Fig. 4a.

From 90 diabetic patients, 89 had their baseline A1c levels measured. These patients were grouped into tertiles of A1c (<7.0, $\mathrm{n}=47 ; 7.0-8.0, \mathrm{n}=15 ;>8.0, \mathrm{n}=27)$. No difference was also found regarding PMI on CMR (19.1\% versus $13.3 \%$ versus $22.2 \%, P=0.88)$. These results are shown in Fig. $4 \mathrm{~b}$.

\section{Discussion}

The analysis of the data from this study shows that patients with diabetes have similar myocardial sensitivity to that of nondiabetic patients after revascularization interventions. The evidence of similar release of both cardiac biomarkers (troponin and CK-MB) after three distinct revascularization strategies, PCI, on-pump, or off-pump CABG, was confirmed by the findings of a high-sensitive and specific imaging technique to detect cardiac ischemic damage, the cardiac magnetic resonance, by the analysis of necrosis as well as myocardial edema.

Although the release of markers of myocardial necrosis after interventions are multifactorial and do not necessarily represent ischemic insults, the findings of myocardial necrosis and edema at CMR are mostly related to ischemic events during cardiac procedures and can be considered as strong evidence to confirm these findings in our sample. In fact, the strength of the present study lies in the assessment of multiple time points of both 


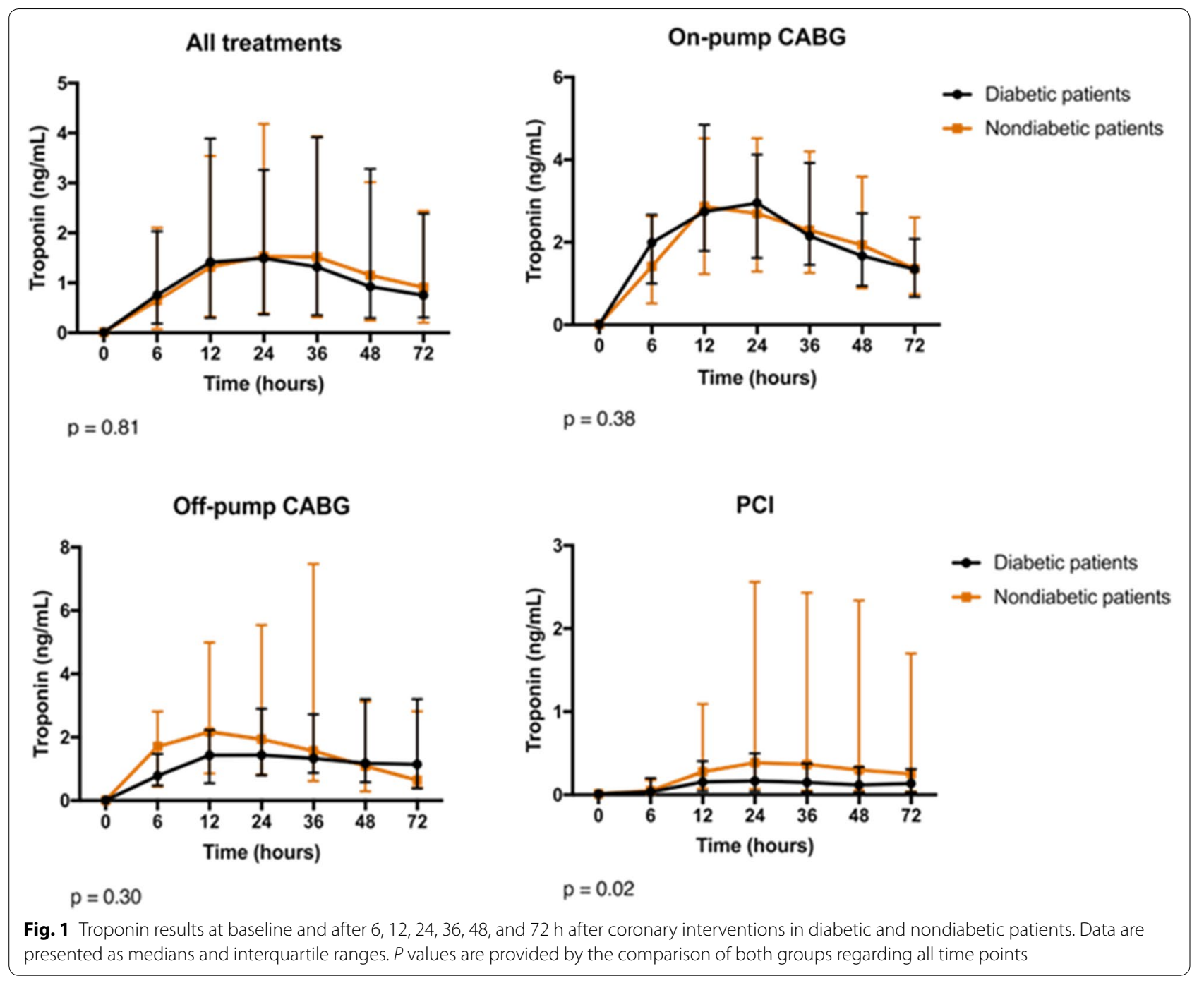

cardiac biomarkers collected in a standardized fashion, with a minimum loss of data, and by bringing the relevant information of CMR results, for both myocardial necrosis and edema. Thus, the analysis of the release of these biomarkers and the findings of cardiac resonance shows similar myocardial sensitivity between diabetic and nondiabetic patients in this sample.

An interesting study from Verdoia et al. evaluated the effect of diabetes in PMI and myonecrosis after PCI treatment [18]. Using the release of CK-MB and troponin to define PMI and myonecrosis, the authors found that diabetes is not associated with increased risk of cardiac damage after PCI therapy. Thus, their findings agree with the results from the present study. However, adding to the information from that study, the present one also assessed the release of biomarkers after on-pump and off-pump bypass surgery and the evaluation of cardiac magnetic resonance.
Other studies have assessed the release of cardiac biomarkers in the setting of acute coronary syndromes and also evaluated mortality rates in diabetic patients [13, 19-22]. Interestingly, although the majority of them have found higher mortality rates in the diabetic population, the release of cardiac biomarkers was similar to that in the nondiabetic population, the same finding seen in the present study after coronary interventions. Thus, these studies show that myocardial sensitivity is probably not influenced by diabetes status, and other factors might be associated with the higher morbidity and mortality rates observed in the diabetic population. Potential reasons for this observation are speculative and still under debate, but might include greater extent of coronary artery disease [23], systolic dysfunction [24], diastolic dysfunction [8], and a theoretically pro-thrombotic state that might be associated with diabetes [25]. Although some argue 


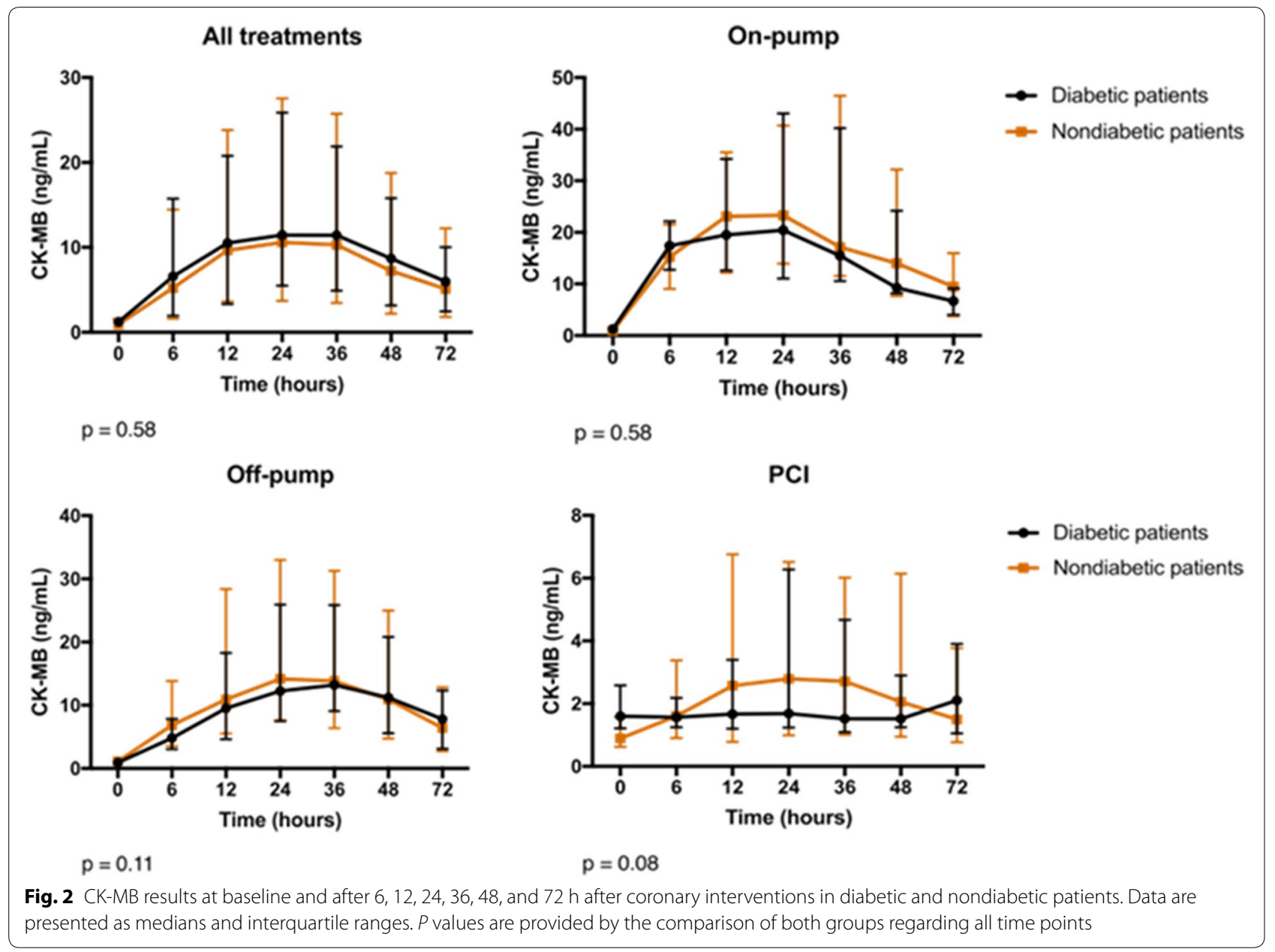

Fig. 2 CK-MB results at baseline and after 6, 12, 24, 36, 48, and $72 \mathrm{~h}$ after coronary interventions in diabetic and nondiabetic patients. Data are presented as medians and interquartile ranges. $P$ values are provided by the comparison of both groups regarding all time points

\section{CMR results}

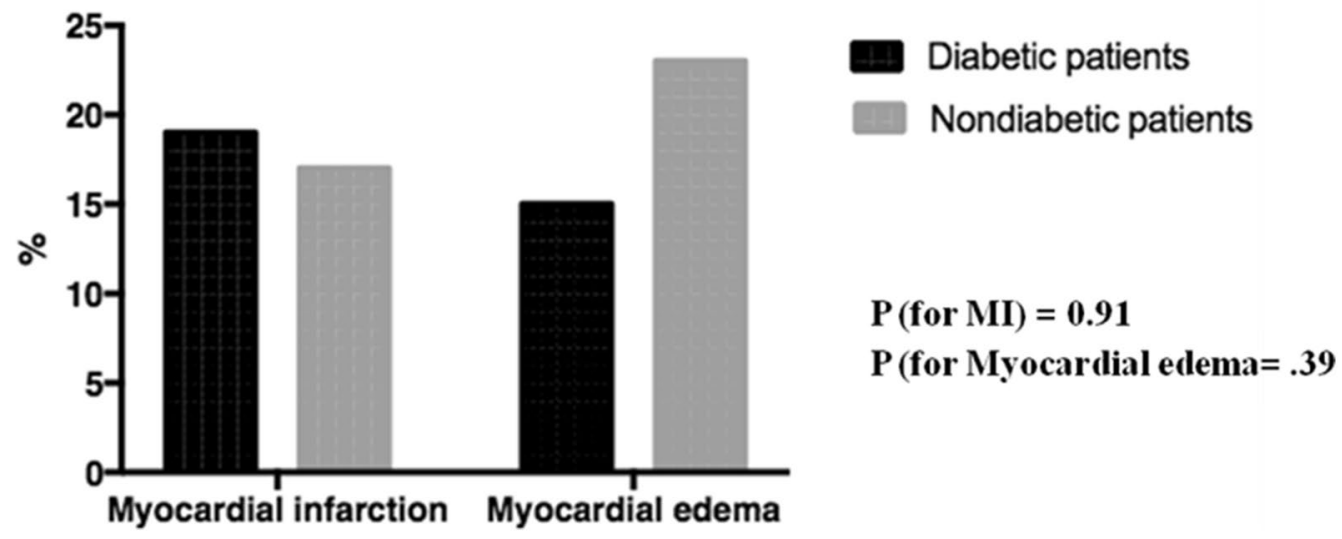

Fig. 3 Myocardial fibrosis and edema after coronary interventions in diabetic and nondiabetic patients, according to CMR analyses 


\section{a PMI according to Glycaemic levels}

\section{b PMI according to A1c levels}

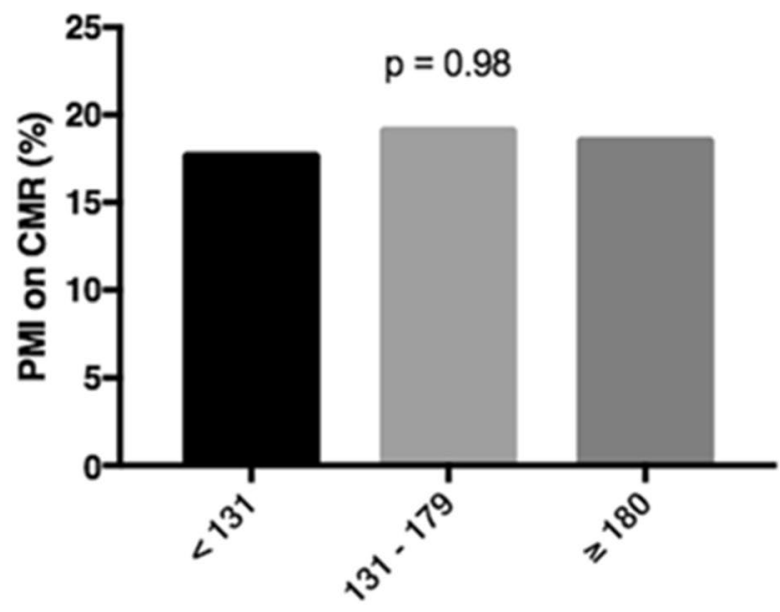

Glycaemic levels (mg/dL)

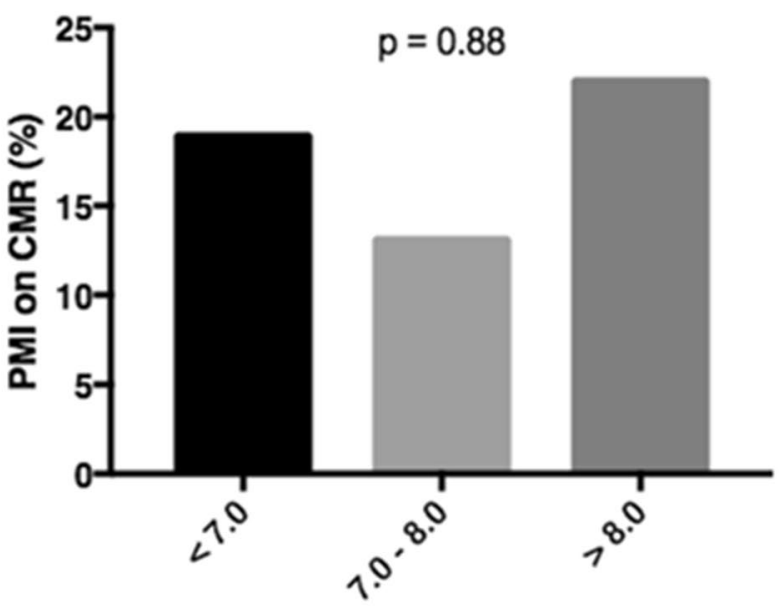

A1c levels (\%)

Fig. 4 a, b Proportion of periprocedural myocardial infarction on cardiac magnetic resonance according to glycemic (a) and A1c (b) levels at baseline

that myocardial intrinsic properties such as ischemic preconditioning might be altered by diabetes [26], our group has recently shown similar findings between diabetic and nondiabetic patients who underwent sequential exercise tests, as part of a preconditioning protocol [27].

In agreement with the findings of this study, Alegria et al. [28] have also evaluated mortality rates at 6 months and infarct size by myocardial scintigraphy in patients who suffered an acute myocardial infarction treated by thrombolytic therapy. They have shown higher mortality rates associated with diabetes that persisted after adjustment for confounding factors. However, this higher mortality could not be totally explained by very modest differences in myocardial infarct size and reduced ejection fraction in diabetic patients. Moreover, the authors could not completely rule out that these very small differences could not still be due to the remaining influence of confounders.

Furthermore, a recent study by Grodzinsky et al. [29] has also assessed angina symptoms over 1 year after PCI treatment. In this study, angina prevalence and severity were similar between patients with and without diabetes. These findings also confirm the findings of the present study: ischemia assessed by the presence of angina and its effects in the myocardium of patients after coronary interventions occur independently of diabetes status.

Interestingly, the analysis of correlation between glycemic and A1c levels and peak troponin and CK-MB did not show any correlation among these variables, although graphically it seems that the higher levels of troponin and CK-MB were found in the lower levels of glycemia. These findings might probably be because the higher peak levels of cardiac markers occurred within the most frequent observations of glycemic levels. In addition, the correlation coefficients do not support any further conclusions. These results are also confirmed by the analysis of cardiac damage assessed by magnetic resonance that did not show any association of PMI with glycemic and A1c level groups at baseline.

The results from this study deserve some consideration. First, it is possible that the small sample size could limit the study power to detect differences between the two populations. On the other hand, the multiple measurements of cardiac biomarkers in addition to the findings of cardiac resonance make this possibility less reasonable. Second, the well-controlled glycemic status, noted by the well-controlled levels of fasting glycemia and A1c in the diabetic population might have influenced study findings. Different findings could be observed in a diabetic population with poor controlled glycemic levels.

\section{Conclusions}

In this study, type 2 diabetes mellitus did not add risk to the development of myocardial injury after percutaneous coronary intervention or bypass surgery in patients with multivessel coronary artery disease. 


\section{Abbreviations}

A1c: glycated hemoglobin; CABG: coronary artery bypass graft; CAD: coronary artery disease; CMR: cardiac magnetic resonance; IQR: interquartile range; LGE: late gadolinium enhancement; MASS V: medicine, angioplasty, or surgery study V; PCl: percutaneous coronary intervention; PMI: periprocedural myocardial infarction; Tnl: troponin I.

\section{Authors' contributions}

PCR researched the data, performed the statistical analysis, and wrote the manuscript. RMR researched the data and reviewed the manuscript. TLS, DFCA, and CLG reviewed the manuscript and made important suggestions to the analysis of the data. CAWS reviewed the manuscript and the statistical analysis. WH conceived the study, contributed to the discussion, and reviewed the manuscript. JAFR and RKF reviewed/edited the manuscript. All authors read and approved the final manuscript.

\section{Acknowledgements}

We thank all members of the MASS Research Team at the Heart Institute (InCor) of the University of São Paulo for the hard work in this project. Medical writing support was provided by Ann Conti Morcos of MorcosMedia during the preparation of the paper, supported by the Zerbini Foundation.

\section{Competing interests}

The authors declare that they have no competing interests.

\section{Availability of data and materials}

The datasets used and analyzed during the current study are available from the corresponding author on reasonable request.

\section{Consent for publication}

Not applicable.

\section{Ethics Approval and consent to participate}

All patients provided written informed consent prior to inclusion in this study. The Ethics Committee of the Heart Institute of the University of São Paulo Medical School, São Paulo, Brazil, approved the trial. All procedures were performed in accordance with the Declaration of Helsinki.

\section{Funding}

Financial support was provided by a research grant from the Zerbini Foundation, São Paulo, Brazil.

\section{Publisher's Note}

Springer Nature remains neutral with regard to jurisdictional claims in published maps and institutional affiliations.

Received: 19 July 2017 Accepted: 15 November 2017

Published online: 21 November 2017

\section{References}

1. Zhang Z, Kolm P, Boden WE, Hartigan PM, Maron DJ, Spertus JA, et al. The cost-effectiveness of percutaneous coronary intervention as a function of angina severity in patients with stable angina. Circ Cardiovasc Qual Outcomes. 2011:4(2):172-82.

2. Dagenais GR, Lu J, Faxon DP, Kent K, Lago RM, Lezama C, Bypass Angioplasty Revascularization Investigation 2 Diabetes (BARI 2D) Study Group, et al. Effects of optimal medical treatment with or without coronary revascularization on angina and subsequent revascularizations in patients with type 2 diabetes mellitus and stable ischemic heart disease. Circulation. 2011;123(14):1492-500.

3. Domanski MJ, Mahaffey K, Hasselblad V, Brener SJ, Smith PK, Hillis G, et al. Association of myocardial enzyme elevation and survival following coronary artery bypass graft surgery. JAMA. 2011;305(6):585-91.

4. Thygesen K, Alpert JS, Jaffe AS, Simoons ML, Chaitman BR, White HD, Joint ESC/ACCF/AHAMWF Task Force for Universal Definition of Myocardial Infarction. Third universal definition of myocardial infarction. J Am Col Cardiol. 2012:60(16):1581-98.
5. Moussa ID, Klein LW, Shah B, Mehran R, Mack MJ, Brilakis ES, et al. Consideration of a new definition of clinically relevant myocardial infarction after coronary revascularization: an expert consensus document from the Society for Cardiovascular Angiography and Interventions (SCAI). J Am Col Cardiol. 2013:62(17):1563-70.

6. Barsotti A, Giannoni A, Di Napoli P, Emdin M. Energy metabolism in the normal and in the diabetic heart. Curr Pharm Des. 2009;15(8):836-40.

7. Paulson DJ. The diabetic heart is more sensitive to ischemic injury. Cardiovasc Res. 1997;34(1):104-12.

8. di Filippo C, Marfella R, Cuzzocrea S, Piegari E, Petronella P, Giugliano D, et al. Hyperglycemia in streptozotocin-induced diabetic rat increases infarct size associated with low levels of myocardial $\mathrm{HO}-1$ during ischemia/reperfusion. Diabetes. 2005;54(3):803-10.

9. Matsumoto S, Cho S, Tosaka S, Ureshino H, Maekawa T, Hara T, et al. Pharmacological preconditioning in type 2 diabetic rat hearts: the roles of mitochondrial ATP-sensitive potassium channels and the phosphatidylinositol 3-kinase-Akt pathway. Cardiovasc Drugs Ther. 2009:23(4):263-70.

10. Feuvray D, Lopaschuk GD. Controversies on the sensitivity of the diabetic heart to ischemic injury: the sensitivity of the diabetic heart to ischemic injury is decreased. Cardiovasc Res. 1997;34(1):113-20.

11. Hadour G, Ferrera R, Sebbag L, Forrat R, Delaye J, Lorgeril M. Improved myocardial tolerance to ischaemia in the diabetic rabbit. J Mol Cell Cardiol. 1998;30(9):1869-75.

12. Korkmaz-Icöz S, Lehner A, Li S, Vater A, Radovits T, Hegedus P, et al. Mild type 2 diabetes mellitus reduces the susceptibility of the heart to ischemia/reperfusion injury: identification of underlying gene expression changes. J Diabetes Res. 2015;2015:396414.

13. Mukamal KJ, Nesto RW, Cohen MC, Muller JE, Maclure M, Sherwood JB, et al. Impact of diabetes on long-term survival after acute myocardial infarction: comparability of risk with prior myocardial infarction. Diabetes Care. 2001;24(8):1422-7.

14. Stone PH, Muller JE, Hartwell T, York BJ, Rutherford JD, Parker CB, The MILIS Study Group, et al. The effects of diabetes mellitus on prognosis and serial left ventricular function after acute myocardial infarction: contribution of both coronary disease and diastolic ventricular dysfunction to the adverse prognosis. J Am Coll Cardiol. 1989;14(1):49-57.

15. Hueb W, Gersh BJ, Alves da Costa LM, Costa Oikawa FT, Vieira de Melo RM, Rezende PC, et al. Accuracy of myocardial biomarkers in the diagnosis of myocardial infarction after revascularization as assessed by cardiac resonance: the medicine, angioplasty, surgery study $V$ (MASS-V) trial. Ann Thorac Surg. 2016:101(6):2202-8.

16. Thygesen K, Mair J, Giannitsis E, Study Group on Biomarkers in Cardiology of ESC Working Group on Acute Cardiac Care, et al. How to use high-sensitivity cardiac troponins in acute cardiac care. Eur Heart J. 2012;33:2252-7.

17. American Diabetes Association. Standards of medical care in diabetes-2016. Diabetes Care. 2016;39(suppl 1):S1-106.

18. Verdoia M, Barbieri L, Schaffer A, Cassetti E, Di Giovine G, Narkin M, on behalf of the Novara Atherosclerosis Study Group (NAS), et al. Effect of diabetes mellitus on periprocedural myocardial infarction in patients undergoing coronary stent implantation. Diabetes Metab Res Rev. 2015:31(1):85-92.

19. Gwilt DJ, Petri M, Lewis PW, Nattrass M, Pentecost BL. Myocardial infarct size and mortality in diabetic patients. Br Heart J. 1985:54(5):466-72.

20. Lehto S, Pyörälä K, Miettinen H, Rönnemaa T, Palomäki P, Tuomilehto J, et al. Myocardial infarct size and mortality in patients with noninsulindependent diabetes mellitus. J Intern Med. 1994;236:291-7.

21. Hasdai D, Granger CB, Srivatsa SS, Criger DA, Ellis SG, Califf RM, et al. Diabetes mellitus and outcome after primary coronary angioplasty for acute myocardial infarction: lessons from the GUSTO-Ilb angioplasty substudy. Global use of strategies to open occluded arteries in acute coronary syndromes. J Am Coll Cardiol. 2000;35:1502-12.

22. Murcia AM, Hennekens CH, Lamas GA, Jimenez-Navarro M, Rouleau $J$, Flaker GC, et al. Impact of diabetes on mortality in patients with myocardial infarction and left ventricular dysfunction. Arch Intern Med. 2004;164:2273-9.

23. Norhammar A, Malmberg K, Diderholm E, Lagerqvist B, Lindahl B, Rydén $L$, et al. Diabetes mellitus: the major risk factor in unstable coronary artery disease and benefits of revascularization. J Am Coll Cardiol. 2004:43:585-91. 
24. Devereux RB, Roman MJ, Paranicas M, O'Grady MJ, Lee ET, Welty TK, et al. Impact of diabetes on cardiac structure and function: the strong heart study. Circulation. 2000;101:2271-6.

25. Nomura S. Dynamic role of microparticles in type 2 diabetes mellitus. Curr Diabetes Rev. 2009;5(4):245-51.

26. Miki T, Miura T, Hotta H, Tanno M, Yano T, Sato T, et al. Endoplasmic reticulum stress in diabetic hearts abolishes erythropoietin-induced myocardial protection by impairment of phosphoblycogen synthase kinase-3betamediated suppression of mitochondrial permeability transition. Diabetes. 2009;58:2863-72

27. Rezende PC, Rahmi RM, Uchida AH, Alves da Costa LM, Scudeler TL, Garzillo CL, et al. Type 2 diabetes mellitus and myocardial ischemic preconditioning in symptomatic coronary artery disease patients. Cardiovasc Diabetol. 2015;14:66

28. Alegria JR, Miller TD, Gibbons RJ, Yi QL, Yusuf S, for the Collaborative Organization of RheothRx Evaluation (CORE) Trial Investigators. Infarct size, ejection fraction, and mortality in diabetic patients with acute myocardial infarction treated with thrombolytic therapy. Am Heart J. 2007;154:743-50.

29. Grodzinsky A, Kosiborod M, Tang F, Jones PG, McGuire DK, Spertus JA, et al. Residual angina after elective percutaneous coronary intervention in patients with diabetes mellitus. Circ Cardiovasc Qual Outcomes. 2017;10:e003553.

\section{Submit your next manuscript to BioMed Central and we will help you at every step:}

- We accept pre-submission inquiries

- Our selector tool helps you to find the most relevant journal

- We provide round the clock customer support

- Convenient online submission

- Thorough peer review

- Inclusion in PubMed and all major indexing services

- Maximum visibility for your research

Submit your manuscript at www.biomedcentral com/submit 